\title{
A Portuguese Adaptation of the Teruel Orthorexia Scale and a Test of Its Utility with Brazilian Young Adults
}

Perceptual and Motor Skills

$0(0) \mathrm{I}-23$

(C) The Author(s) 2021

Article reuse guidelines: sagepub.com/journals-permissions DOI: I0.1I77/003।5I252II029240 journals.sagepub.com/home/pms

@SAGE

\author{
Wanderson Roberto da Silva'*, \\ Carlos Hernani Cruz Marmol',*, \\ Angela Nogueira Neves ${ }^{2}$, \\ João Marôco ${ }^{3}$, and \\ Juliana Alvares Duarte Bonini Campos'
}

\begin{abstract}
The aims for this study were to perform a Portuguese language cross-cultural adaptation of the Teruel Orthorexia Scale (TOS) and to evaluate the scale's psychometric properties, including verifying the frequency of behaviors characteristic of orthorexia nervosa and healthy orthorexia, among a group of Brazilian gym users. First, we adapted the Spanish version of the TOS to the Brazilian Portuguese language following international protocols to guarantee idiomatic, semantic, conceptual, and cultural equivalence. Then participants completed both the new Portuguese version of the TOS and a socioeconomic questionnaire. Among our sample of 226 young Brazilian adults $\left(63.7 \%\right.$ men; $M_{\text {age }}=28.8, S D=5$.l years $)$, we assessed the bi-factorial model

\footnotetext{
'Department of Biological Sciences, School of Pharmaceutical Sciences, São Paulo State University (UNESP), Araraquara, SP, Brazil

${ }^{2}$ Physical Education School of Brazilian Army, Rio de Janeiro, RJ, Brazil

${ }^{3}$ William James Center for Research (WJCR), ISPA - University Institute, Lisbon, Portugal

*Wanderson R. da Silva and Carlos H. C. Marmol should be considered joint first author.

Corresponding Author:

Wanderson Roberto da Silva, Department of Biological Sciences, School of Pharmaceutical Sciences, São Paulo State University, Rodovia Araraquara-Jaú, km0I, 14800-903 Araraquara/SP, Brazil.

Email: wandersonroberto22@gmail.com
} 
of the TOS through factorial, convergent, and discriminant validity, reliability, and factorial invariance. We calculated the mean scores of the TOS factors and the frequency of behaviors of both orthorexia nervosa and healthy orthorexia. The new Portuguese version was well understood by participants, and the TOS bifactorial model presented adequate psychometric properties and showed invariance in independent subsamples and in men and women. The mean scores were different between sexes only for orthorexia nervosa, with women obtaining higher values. The frequency of orthorexia nervosa behaviors was $5.3 \%$ and of healthy orthorexia was $41.2 \%$. Based on these findings, the Brazilian Portuguese version of the TOS can be a useful tool for investigating orthorexia-like behaviors in future research.

\section{Keywords}

orthorexia, scale, validation, cross-cultural adaptation, gym users

\section{Introduction}

The term orthorexia nervosa was coined by Bratman (1997) to refer to a preoccupation with intake of healthy food that is obsessive to the point that it leads to more harmful than beneficial consequences (Bratman, 2017). A factor that strongly contributes to the development of this condition is having distorted beliefs (e.g., the idea that all foods containing gluten are unhealthy) that can lead to such negative consequences as nutrient deficiency, excessive weight loss, social isolation, and guilt when violating the imposed diet restrictions (Cena et al., 2019; Dunn \& Bratman, 2016). Thus, it is important to investigate orthorexia nervosa in order to identify risky eating behaviors and help individuals develop behaviors that will reduce the negative physiological and psychosocial effects of this condition (McComb \& Mills, 2019).

Although the negative outcomes of orthorexia nervosa have been studied (Cena et al., 2019; Dunn \& Bratman, 2016; McComb \& Mills, 2019; Novara et al., 2021), there is no consensus as to whether it represents a unique, independent mental disorder or is better considered a subtype of an existing disorder (e.g., other eating disorders; obsessive-compulsive disorder). Orthorexia nervosa is not listed separately in the Diagnostic and Statistical Manual of Mental Disorders (DSM-5; American Psychiatric Association, 2013) or in the International Classification of Diseases (ICD-11; World Health Organization, 2018). As there is no universal set of criteria for diagnosing orthorexia nervosa, clinical and experimental studies have often relied upon psychometric instruments to investigate its characteristics. These instruments have included the Bratman's Orthorexia Self-test-BOT (Bratman \& Knight, 2000), ORTO-15 Test (Donini et al., 2005), Eating Habits Questionnaire-EHQ (Gleaves et al., 
2013), Dusseldorf Orthorexia Scale-DOS (Barthels et al., 2015), Barcelona Orthorexia Scale-BOS (Bauer et al., 2019), Orthorexia Nervosa InventoryONI (Oberle et al., 2021), and the Teruel Orthorexia Scale-TOS (Barrada \& Roncero, 2018). Systematic reviews (Cena et al., 2019; McComb \& Mills, 2019; Valente et al., 2019) have reported some advantages and disadvantages of these instruments.

The BOT was the first questionnaire developed to assess orthorexia nervosa, but it was shown to have limited validity (Bratman \& Knight, 2000; Valente et al., 2019). The ORTO-15 is the most commonly used instrument, but it has been criticized (Cena et al., 2019; Missbach et al., 2017; Mitrofanova et al., 2021; Valente et al., 2019) for overestimating orthorexia nervosa and for having weak psychometric properties (low reliability and limited validity). The EHQ has conceptualized the overwhelming preoccupation with eating healthy among individuals with orthorexia nervosa; but, a validity concern was that this tool does not consider negative emotions, such as sadness and guilt, that are often associated with orthorexia nervosa (Gleaves et al., 2013; Valente et al., 2019). The DOS was proposed to investigate a pathological fixation on a healthy diet, but it has not seemed able to differentiate between anorexic and orthorexic behaviors (Barthels et al., 2015; Valente et al., 2019). The BOS was also developed to address pathological fixation on healthy food intake, but the authors themselves identified its limitations, noting that not all the specialists involved in its development had advanced knowledge of orthorexia nervosa (Bauer et al., 2019; Valente et al., 2019). The ONI assesses behaviors and preoccupations with healthy eating, physical and psychosocial impairments, and emotional distress, and the initial ONI study (Oberle et al., 2021) showed adequate psychometric properties for it. However, the ONI was developed after the start of the present study and it has not yet been used in other studies. On the other hand, the TOS was developed to assess excessive preoccupation with eating believed to be healthy, and this tool includes items addressing both pathological and nonpathological aspects of this tendency. In previous studies with Spanish participants (Barrada \& Roncero, 2018; Barthels et al., 2019), the TOS showed good psychometric properties, making it a promising instrument for assessing orthorexia.

The TOS was developed by Barrada and Roncero (2018). As noted, it includes items on a pathological dimension of a healthy eating preoccupation (i.e., orthorexia nervosa) and non-pathological items for detecting healthy eating interest, called healthy orthorexia. Healthy orthorexia is the interest in adequate nutrition as part of a non-extreme practice to maintain the balance between health and well-being (Bratman, 2017). However, given the recent publication of the scale in the scientific literature, few studies have used the TOS, and as far as we know, only four studies (Domingues \& Carmo, 2021; Strahler, 2020, 2021; Strahler et al., 2020) applied the instrument in non-Spanish samples. 
There have been few investigations of orthorexia in the Brazilian population, and few existing studies have used the ORTO-15 (Alvarenga et al., 2012; Lorenzon et al., 2020), as this has been the only instrument for this purpose that is available in Portuguese. The sparse research in this area might be associated with the low internal consistency (alpha $[\alpha]$ range $=.31-.63$ ) of the ORTO-15 (Alvarenga et al., 2012) and a greater interest in assessing recognized eating disorders, such as anorexia and bulimia nervosa (Barthels et al., 2019; Bratman, 2017). Therefore, for assessing and researching orthorexia behaviors in Brazil, the TOS would be useful. However, in order to establish this instrument's validly and reliability for Brazilian samples, a cross-cultural adaptation of the TOS from Spanish to Portuguese is required. Of note, as with any psychometric tool, there is also a need for a psychometric assessment of the TOS (Marôco, 2021) before interpreting its results (e.g., scores), especially for identifying or describing specific groups of individuals who may exhibit unusual eating behaviors. Obsessive and inflexible eating behaviors are common among athletes and serious exercisers (Bert et al., 2019; Segura-Garcia et al., 2012). Bratman (2017) pointed out that a high frequency of physical activity can be associated with behaviors related to orthorexia nervosa. Our interest in applying the TOS to the study of orthorexia nervosa in Brazil had three objectives: (a) perform a cross-cultural adaptation of the TOS to the Portuguese language, (b) evaluate the psychometric properties of the scale when applied to a sample of Brazilian young adults who regularly exercise within gyms, and (c) calculate the frequency of behaviors of both orthorexia nervosa and healthy orthorexia among these participants.

\section{Method}

\section{Participants}

This was an observational, cross-sectional study of gym users of both sexes who went to gyms in Araraquara/SP, Brazil. Participant inclusion criteria were: (a) 18 years of age or older, (b) workout frequency of at least three days a week, and (c) being literate. Exclusion criteria were: (a) women who were pregnant, lactating, or puerperal, (b) $>60$ years of age, (c) blindness, and (d) under treatment for any eating disorder, as determined by self-report.

To recruit participants, we first contacted the owners of 12 fitness clubs and gyms in person or by e-mail and invited them to participate in the research. Those five clubs who answered the invitation received a letter with information about the purposes of the study, and all of these owners agreed to allow a trained researcher to collect data from users of the establishment. Next, we recruited individual participants in person at the gyms, and all participants provided written informed consent before engaging in any research activities. 
The study was approved by the Research Ethics Committee of the university where the study was conducted (CAAE: 22051619.8.0000.5426).

\section{Participant Procedure}

We collected participant information on age, sex, marital status, work activity, race (self-reported according to the Brazilian Institute of Geography and Statistics), self-reported eating disorder (i.e., diagnosed by a therapist in the past), intake of anabolic steroids and dietary supplements to improve body appearance, weekly workout frequency, body-changing diet, and selfassessment of diet quality. Body weight and height were self-reported, and the values were used to calculate body mass index (BMI) and to obtain the anthropometric nutritional status (De Onis et al., 2007; World Health Organization, 2000). Level of education and economic class were obtained using the criteria established by the Brazilian Market Research Association (ABEP, 2020). This includes information regarding the number of household durable consumer items (e.g., washing machines and personal computers), householder's education, and access to public services (e.g., basic sanitation). Each item corresponds to one point on the scale, and the total sum represents the score used to determine the family's economic class (e.g., $0-16$ points $=$ class D-E - i.e., low; $45-$ 100 points: class $\mathrm{A}-$ i.e., high).

Gym users who agreed to participate through written informed consent and who met inclusion and exclusion criteria for continuing in the study, completed a socioeconomic questionnaire, the TOS, and the Social Appearance Anxiety Scale (SAAS) in paper format in a reserved place without the researcher present. Participants were asked to complete all the scales (there were no missing values). We used a numbering system to identify respondents to guarantee anonymity during database entry (omitting the identification page). A total of 226 individuals completed the measures $(63.7 \%$ men; $M$ age $=27.8, S D=5.1$ years; $M$ $\mathrm{BMI}=24.9, S D=3.7 \mathrm{~kg} / \mathrm{m}^{2}$ ).

\section{Measures}

Teruel Orthorexia Scale (TOS). The TOS was originally developed in Spanish (Barrada \& Roncero, 2018) to assess characteristics of orthorexia, considering both pathological and non-pathological aspects of this construct. This Spanish instrument has 17 items with a 4-point Likert-type response format, ranging from 0 (do not agree) to 3 (strongly agree) and a bi-factorial model (orthorexia nervosa: items 4, 5, 9, 10, 12, 14, 16, 17; healthy orthorexia: items $1,2,3,6,7,8$, $11,13,15)$. According to Barrada and Roncero (2018), people with high scores (calculated by the sum of items) on the healthy orthorexia factor are interested in healthy eating, while individuals with high scores on the orthorexia nervosa factor are highly concerned with and overwhelmed by their preoccupations. However, there are no cutoff points to classify the scores. The TOS items 
were developed from previous theoretical studies on orthorexia behaviors. In the original study (Barrada \& Roncero, 2018), the TOS bi-factorial model showed good factorial validity (Root Mean Square Error of Approximation $[\mathrm{RMSEA}]=.06$, Comparative Fit Index $[\mathrm{CFI}]=.96$, Tucker-Lewis Index $[\mathrm{TLI}]=.95$ ) and good internal consistency (Cronbach's $\alpha$ : healthy orthorexia $=.81$, orthorexia nervosa $=.85$ ) for a sample of individuals from a Spanish community, most of whom were female university students. Subsequent studies also showed the TOS to have good psychometric properties (Barthels et al., 2019; Strahler et al., 2020). We requested and received the TOS authors' authorization to use the TOS for cross-cultural adaptation.

Social Appearance Anxiety Scale (SAAS). We also applied the SAAS in order to assess the relationship between the participants' social anxiety due to physical appearance and the two TOS factors. This scale was developed by Hart et al. (2008) as a unidimensional measure. It is composed of 16 items rated on a 5-point Likerttype response format ranging from 1 (not at all) to 5 (extremely); and it has a single factor. The degree of social appearance anxiety is measured by summing all 16 items into one total score. The factorial model of the SAAS showed adequate fit $(\mathrm{RMSEA}=.09, \mathrm{CFI}=.98, \mathrm{TLI}=.98$, Standardized Root Mean Square Residual $[\mathrm{SRMR}]=.05$ ) and good reliability (ordinal $\alpha=.97$, omega coefficient $[\omega]=.96$, nonlinear structural equation modeling reliability coefficient $\left.\left[\rho_{\mathrm{NL}}\right]=.97\right)$ for data.

\section{TOS Adaptation and Cross-Validation Procedure}

For the cross-cultural adaptation of the TOS to the Portuguese language, we evaluated the idiomatic, semantic, conceptual, and cultural equivalences of the TOS (Beaton et al., 2000; Reichenheim \& Moraes, 2007). Three bilingual Brazilian researchers with advanced knowledge of the Spanish language and no previous knowledge of the TOS independently translated the TOS. The three versions obtained were analyzed by the authors who agreed to a single or intermediate version that was then sent to a back-translator to assess its semantic equivalence to the original TOS. This back-translation was performed by a native Spanish researcher with advanced knowledge of Brazilian Portuguese and no knowledge of the TOS. Then, the back-translated version was compared with the original version for content similarity, thus attesting to the adequacy of the new Portuguese version.

Next, three experts in nutrition, psychometrics, and physical exercise assessed the conceptual and cultural equivalences and verified whether the new Portuguese version was consistent with the original theoretical construction of the TOS and whether the content was suitable for the Brazilian culture. In this process, the only suggested alteration was replacing the phrase "ordinary people" in item three (in Spanish: "común de la gente"; in Portuguese: "pessoas 
comuns") with "most people" (in Spanish: "la mayoría de las personas"; in Portuguese: "a maioria das pessoas"). In addition, in order to be able to use the TOS in Portugal, a native Portuguese specialist assessed the Brazilian version and attested that it was understandable.

We tested the Brazilian Portuguese version of the TOS in a pilot study with 30 Brazilian gym users (women $=56.7 \% ; M_{\text {age }}=26.0, S D=6.2$ years) to verify that it was understandable (Coluci \& Alexandre, 2009). These participants also provided written informed consent before engaging in the research. As most of these participants gave assurance for the instrument's instructions $(86.2 \%)$, the content of the items $(82.8 \%)$, and the answer options $(79.3 \%)$, we used the Brazilian Portuguese version of the TOS to carry out further psychometric analyses. Table 1 shows the final Brazilian Portuguese version of the TOS.

\section{Data Analysis}

Minimum sample size was determined by the Monte-Carlo simulation as suggested by Brown (2015). The simulation was performed using estimates (i.e., factorial loadings, correlation between factors, and thresholds) from the original TOS study (Barrada \& Roncero, 2018). A total of 1,000 replications employing sample sizes of 50,100,150,200, and 300 were simulated using criteria defined by Muthén and Muthén (2017). A sample size of 150 was shown to be enough to achieve $<1 \%$ bias for both parameters and their standard errors, coverage of the $95 \%$ confidence interval $(\mathrm{CI}) \geq 93 \%$, and power of $100 \%$.

We assessed measures of data distribution and central tendency for all the TOS items. We investigated the construct validity of the TOS through factorial, convergent, and discriminant validity analyses (Anastasi \& Urbina, 1997). We did not use additional measures to assess convergent and discriminant validity, since these properties were estimated using indices as recommended by Fornell and Larcker (1981).

For factorial validity, the TOS measurement model (bi-factorial) was evaluated by confirmatory factor analysis. The estimation method used was the Weighted Least Squares Mean and Variance Adjusted (WLSMV), and the quality of the fit was assessed by RMSEA with $90 \%$ CI, CFI, TLI, and SRMR. When RMSEA $\leq .10$, CFI and TLI $\geq .90$, and SRMR $<.09$ the model fit was considered acceptable (Hair Jr. et al., 2019; Hu \& Bentler, 1999; Marôco, 2021). The factor loading $(\lambda)$ of each item was also assessed, and values $>.50$ were considered adequate. To assess convergent validity, the average variance extracted (AVE) was calculated for each factor, and values above .50 were considered adequate (Fornell \& Larcker, 1981; Marôco, 2021). To assess discriminant validity, we compared the AVE values obtained for each factor with the coefficient of determination $\left(r^{2}\right)$. To be adequate, both AVE values must be equal or greater than $r^{2}$ (Fornell \& Larcker, 1981). To assess the concurrent and divergent validity, we conducted a correlation analysis (Marôco, 2021) among 
Table I. Spanish (original) and Brazilian Portuguese Versions of the Teruel Orthorexia Scale.

Spanish (original) ${ }^{\mathrm{a}}$

Las siguientes preguntas se relacionan con las ideas y actitudes que tienes en relación con la alimentación. En concreto, nos gustaría saber hasta qué punto para ti es importante seguir una alimentación sana o consumir alimentos como, por ejemplo, aquellos libres de grasa, sal, conservantes, aditivos hechos por el ser humano o cualquier sustancia que consideres nociva o tóxica, como herbicidas o pesticidas.

$0=$ Nada de acuerdo,

$I=$ Algo de acuerdo,

2 = Bastante de acuerdo,

$3=$ Muy de acuerdo

I. Me siento bien cuando como comida sana

2. Empleo gran cantidad de tiempo en comprar, planificar y/o preparar la comida para que mi alimentación sea lo más saludable posible

3. Considero que mi modo de alimentarme es más sano al del común de la gente

4. Me siento culpable cuando como algún alimento que considero no sano

5. Mis relaciones sociales se han visto afectadas negativamente a causa de mi preocupación por comer alimentos sanos

6. Mi interés por una alimentación sana es una parte importante de mi forma de ser, de entender el mundo

7. Prefiero comer un alimento sano y poco sabroso que un alimento de buen sabor que no sea sano

8. Como principalmente alimentos que considero sanos
Brazilian Portuguese $^{b}$

Instruções: As seguintes afirmações estão relacionadas com as ideias e atitudes que você tem em relação à alimentação. Gostaríamos de saber até que ponto é importante para você seguir uma alimentação saudável ou consumir alimentos como, por exemplo, aqueles livres de gordura, sal, conservantes, aditivos sintetizados por humanos ou qualquer substância que você considere nociva ou tóxica, como herbicidas e pesticidas.

Opções de resposta:

$0=$ não concordo,

$\mathrm{I}=$ concordo um pouco,

2 = concordo bastante,

3 = concordo fortemente

I. Eu me sinto bem quando como comida saudável

2. Eu gasto muito tempo para comprar, planejar e/ou preparar as refeições para que minha alimentação seja o mais saudável possível

3. Eu considero que minha alimentação é mais saudável do que da maioria das pessoas

4. Eu me sinto culpado(a) quando como algum alimento que considero não saudável

5. As minhas relações sociais já foram afetadas negativamente por causa da minha preocupação em comer alimentos saudáveis

6. O meu interesse por uma alimentação saudável é uma parte importante do meu jeito de ser, de entender o mundo

7. Prefiro comer um alimento saudável e pouco saboroso do que um alimento saboroso que não seja saudável

8. Eu como principalmente alimentos que considero saudáveis 
Table I. Continued.

Spanish (original) ${ }^{\mathrm{a}}$

9. Mi preocupación por la alimentación sana me consume mucho tiempo

10. Me preocupa la posibilidad de comer alimentos poco saludables

II. No me importa gastar más dinero en un alimento si lo considero más sano.

12. Me siento agobiado/a o triste si como alimentos que no considero sanos

13. Prefiero comer poco, pero sano, a quedar saciado/a con comida que pueda no ser sana

14. Evito comer con gente que no comparte mis ideas sobre alimentación sana

15. Intento convencer a la gente de mi alrededor para que siga mis hábitos de alimentación saludable

16. Si en algún momento como algo que considero no sano, me castigo por ello

17. Los pensamientos sobre alimentación saludable no me dejan concentrarme en otras tareas
Brazilian Portuguese ${ }^{b}$

9. A minha preocupação com a alimentação saudável me consome muito tempo

10. Eu me preocupo com a possibilidade de comer alimentos pouco saudáveis

II. Eu não me importo de gastar mais dinheiro com um alimento se eu o considero mais saudável

12. Eu me sinto angustiado(a) ou triste quando como alimentos que não considero saudáveis

13. Eu prefiro comer pouco, mas de forma saudável, do que ficar saciado(a) com uma comida que possa não ser saudável

14. Eu evito comer com pessoas que não compartilham minhas ideias sobre alimentação saudável

I5. Eu tento convencer as pessoas ao meu redor para que sigam os meus hábitos de alimentação saudável

16. Se em algum momento como algo que eu considero não saudável, eu me castigo por isso

17. Os meus pensamentos sobre alimentação saudável não me deixam concentrar em outras tarefas

Note. Factors: Healthy Orthorexia $=$ items I, 2, 3, 6, 7, 8, II, I3, and I5; Orthorexia Nervosa $=$ items 4, 5, $9,10,12,14,16$, and 17.

${ }^{a}$ Version produced by the Barrada and Roncero (2018).

${ }^{b}$ Version produced in this study following protocols for cross-cultural adaptation.

the TOS and SAAS scores. Ideally, orthorexia nervosa and social appearance anxiety should be highly correlated, while healthy orthorexia and social appearance anxiety should be weakly correlated.

We also analyzed the reliability of the TOS factors using $\rho_{\mathrm{NL}}$ (Kim et al., 2020; Yang \& Green, 2015). In addition, the ordinal $\alpha$ and $\omega$ (Gadermann et al., 2012; Zumbo et al., 2007) were computed as measures of hypothetical reliability for comparative purposes with previous studies. Values equal to or greater than .80 were considered adequate (Cicchetti, 1994).

After adjusting the factorial model of the TOS to the data, we performed a test for the invariance of independent subsamples to investigate the measure's external validity (i.e., how well the results from the first sample can be 
generalized to other samples from the same study population). The total sample was randomly divided into two equal parts, and multigroup analysis was done using the chi-square difference test statistic $\left(\Delta \chi^{2}\right)$. Invariance was confirmed when $\lambda$, thresholds $(\mathrm{t})$, and residuals (res) did not differ significantly $(p>.05)$ between the metric, scalar, and strict levels, respectively (Marôco, 2021). This analysis was also carried out using male and female subsamples with the same criteria.

The mean for each factor of the TOS was used to calculate the scores for healthy orthorexia and orthorexia nervosa. In addition, we compared the mean scores between men and women using analysis of variance (ANOVA) and verified their relationship with age and BMI through Pearson's correlation, with $5 \%$ level of significance. The assumption of data normality was met, based on the psychometric sensitivity of the items in the scale. We classified participants according to the likelihood of presenting behaviors of orthorexia nervosa and healthy orthorexia. This classification was performed using the 25, 50, and 75 percentiles (P) of Likert-type response scale of the TOS and scores as follows: $\leq .75 \quad(\mathrm{P} \leq 25)=$ extremely unlikely, $.75 \nmid 1.50 \quad(\mathrm{P} 25-50)=$ unlikely, $1.50 \nmid 2.25$ $(\mathrm{P} 50-75)=$ likely; $>2.25 \quad(\mathrm{P}>75)=$ extremely likely. The percentiles do not refer to the sample distribution, but rather divide the possible response values (i.e., Likert-type scale) into four sections. Next, we calculated the frequency of participants in each category with a $95 \%$ CI. We used SPSS Statistics for Windows, version 22.0 (Armonk, NY: IBM Corp.) and R v.3.6.2 ("lavaan", "semTools", "pbivnorm", and "psych" packages) for data analysis (Genz et al., 2015; Jorgensen et al., 2020; Revelle, 2019; Rossel, 2012).

\section{Results}

Details about the study sample are shown in Table 2.

As noted, most participants were single, of white race, had a job, and had achieved higher education. In addition, most individuals classified their diet as normal/good, reported never having been diagnosed with an eating disorder, and were not using anabolic steroids for body enhancement. On the other hand, the use of dietary supplements and body-changing diets were reported by most participants and most went to the gym more than five times a week. In addition, the majority of this sample presented adequate weight for their height and medium-high economic status (economic class B).

Table 3 shows the summary data and measures of data distribution for the TOS items; high values of skewness and/or kurtosis were observed only in items 14,16 , and 17.

Regarding the factorial validity, an adequate fit of the TOS bi-factorial model $(\mathrm{RMSEA}=.09[90 \% \mathrm{CI}=.07-.10], \mathrm{CFI}=.94, \mathrm{TLI}=.93, \mathrm{SRMR}=.09)$ and adequate factor loadings $(\lambda=.57-.86)$ were observed for the study sample (Table 3 ). Convergent and discriminant validities were also adequate (AVE: orthorexia 
Table 2. Study Sample Characteristics.

\begin{tabular}{|c|c|c|c|c|c|c|}
\hline \multirow{3}{*}{$\begin{array}{l}\text { Characteristic } \\
\text { Sex }\end{array}$} & \multicolumn{6}{|c|}{ Sample, n (\%) } \\
\hline & \multicolumn{2}{|c|}{ Total } & \multicolumn{2}{|c|}{ Male } & \multicolumn{2}{|c|}{ Female } \\
\hline & & & & & & \\
\hline Male & 144 & $(63.7)$ & 144 & $(63.7)$ & - & - \\
\hline Female & 82 & (36.3) & - & - & 82 & (36.3) \\
\hline \multicolumn{7}{|l|}{ Marital status } \\
\hline Not married & 150 & $(66.4)$ & 85 & $(59.0)$ & 65 & $(79.3)$ \\
\hline Married/common law & 69 & $(30.5)$ & 54 & (37.5) & 15 & (I8.3) \\
\hline Divorced/separated & 7 & (3.1) & 5 & $(3.5)$ & 2 & $(2.4)$ \\
\hline \multicolumn{7}{|l|}{ Work activity } \\
\hline No & 41 & $(18.2)$ & 20 & $(14.0)$ & 21 & $(25.6)$ \\
\hline Yes & 184 & $(81.8)$ & 123 & $(86.0)$ & 61 & $(74.4)$ \\
\hline \multicolumn{7}{|l|}{ Education level } \\
\hline Incomplete Elementary School & - & - & - & - & - & - \\
\hline Elementary School/Incomplete Junior High School & - & - & - & - & - & - \\
\hline Junior High School Diploma/Incomplete High School & 2 & $(1.0)$ & 2 & $(1.5)$ & - & - \\
\hline High School Diploma/Incomplete Higher Education & 78 & $(40.2)$ & 56 & $(43.1)$ & 22 & $(34.4)$ \\
\hline Higher Education Degree & 114 & $(58.8)$ & 72 & $(55.4)$ & 42 & $(65.6)$ \\
\hline \multicolumn{7}{|l|}{ Race } \\
\hline White & 167 & $(74.2)$ & 103 & $(72.0)$ & 64 & $(78.0)$ \\
\hline Black & 12 & $(5.3)$ & 9 & $(6.3)$ & 3 & (3.7) \\
\hline Asian & 4 & $(1.8)$ & I & $(.7)$ & 3 & $(3.7)$ \\
\hline Mixed & 40 & $(17.8)$ & 29 & $(20.3)$ & 11 & $(13.4)$ \\
\hline Native (indigenous) & 2 & $(.9)$ & I & $(.7)$ & I & $(1.2)$ \\
\hline \multicolumn{7}{|l|}{ Self-reported eating disorders } \\
\hline \multicolumn{7}{|l|}{ (diagnosed by a therapist in the past) } \\
\hline No & 218 & $(98.6)$ & $|4|$ & $(99.3)$ & 77 & $(97.5)$ \\
\hline Yes & 3 & $(1.4)$ & I & $(.7)$ & 2 & $(2.5)$ \\
\hline \multicolumn{7}{|l|}{ Use of anabolic steroids } \\
\hline Never & 200 & $(90.1)$ & 123 & $(87.9)$ & 77 & $(93.9)$ \\
\hline Once in life & 13 & (5.9) & 9 & $(6.4)$ & 4 & (4.9) \\
\hline Sometimes & 6 & (2.7) & 5 & (3.6) & I & $(1.2)$ \\
\hline Frequently & 3 & (1.3) & 3 & $(2.1)$ & - & - \\
\hline \multicolumn{7}{|l|}{ Use of food supplements } \\
\hline Never & 59 & $(26.1)$ & 25 & $(17.4)$ & 34 & $(4 I .5)$ \\
\hline Once in life & 21 & $(9.3)$ & 12 & $(8.3)$ & 9 & (II.0) \\
\hline Sometimes & 80 & $(35.4)$ & 58 & $(40.3)$ & 22 & $(26.8)$ \\
\hline Frequently & 66 & $(29.2)$ & 49 & $(34.0)$ & 17 & $(20.7)$ \\
\hline \multicolumn{7}{|l|}{ Weight loss diet } \\
\hline Never & 42 & $(18.7)$ & 28 & $(19.6)$ & 14 & $(\mid 7.0)$ \\
\hline Rarely & 34 & $(15.1)$ & 22 & $(15.3)$ & 12 & $(14.6)$ \\
\hline Sometimes & 75 & (33.3) & 50 & $(35.0)$ & 25 & (30.5) \\
\hline
\end{tabular}


Table 2. Continued.

\begin{tabular}{|c|c|c|c|c|c|c|}
\hline \multirow{3}{*}{$\frac{\text { Characteristic }}{\text { Frequently }}$} & \multicolumn{6}{|c|}{ Sample, n (\%) } \\
\hline & \multicolumn{2}{|c|}{ Total } & \multicolumn{2}{|c|}{ Male } & \multicolumn{2}{|c|}{ Female } \\
\hline & 38 & $(16.9)$ & 20 & $(14.0)$ & 18 & $(22.0)$ \\
\hline Always & 36 & $(16.0)$ & 23 & $(16.1)$ & 13 & $(15.9)$ \\
\hline \multicolumn{7}{|c|}{ Weekly frequency of gym exercise (days) } \\
\hline 3 & 34 & $(15.0)$ & 13 & $(9.0)$ & 21 & $(25.6)$ \\
\hline 4 & 45 & $(19.9)$ & 25 & $(17.4)$ & 20 & (24.4) \\
\hline 5 & 75 & (33.2) & 51 & $(35.4)$ & 24 & (29.3) \\
\hline 6 & 53 & $(23.5)$ & 41 & $(28.5)$ & 12 & $(14.6)$ \\
\hline 7 & 19 & $(8.4)$ & 14 & $(9.7)$ & 5 & (6.I) \\
\hline \multicolumn{7}{|c|}{ Self-perception of own diet } \\
\hline Bad & 12 & (5.3) & 4 & $(2.8)$ & 8 & $(9.8)$ \\
\hline Acceptable & 33 & $(14.6)$ & 17 & $(11.8)$ & 16 & (19.5) \\
\hline Normal & 74 & (32.7) & 43 & $(29.9)$ & 31 & (37.8) \\
\hline Good & 88 & $(38.9)$ & 66 & $(45.8)$ & 22 & $(26.8)$ \\
\hline Great & 19 & $(8.5)$ & 14 & $(9.7)$ & 5 & $(6.1)$ \\
\hline \multicolumn{7}{|c|}{ Anthropometric nutritional status } \\
\hline Underweight & 2 & $(.9)$ & I & $(.7)$ & I & $(1.3)$ \\
\hline Normal weight & 135 & $(59.7)$ & 72 & $(50.0)$ & 63 & (76.8) \\
\hline Overweight & 71 & $(31.4)$ & 60 & $(41.7)$ & II & (13.4) \\
\hline Obesity & 18 & $(8.0)$ & II & $(7.6)$ & 7 & $(8.5)$ \\
\hline \multicolumn{7}{|c|}{$\begin{array}{l}\text { Economy class (average } \\
\text { household income in USD) }\end{array}$} \\
\hline D-E (\$ |42.73) & I & $(.4)$ & I & $(.7)$ & - & - \\
\hline$C(\$ 533.77)$ & 34 & $(15.0)$ & 16 & $(I I .1)$ & 18 & $(22.0)$ \\
\hline $\mathrm{B}(\$ 1,829.43)$ & 136 & $(60.2)$ & 97 & (67.4) & 39 & (47.5) \\
\hline $\mathrm{A}(\$ 3,985.44)$ & 55 & $(24.4)$ & 30 & $(20.8)$ & 25 & (30.5) \\
\hline
\end{tabular}

Note. The race was self-reported according to recommendations of the Brazilian Institute of Geography and Statistics (IBGE). The average household income (ABEP, 2020) in Brazilian reals was converted into American dollars, exchange rate April, 202I: IUSD = 5.7BRL (https://www.bcb.gov.br/conversao).

nervosa $=.58$, healthy orthorexia $=.53 ; r^{2}=.53$ ). We found a medium and significant correlation between orthorexia nervosa and social appearance anxiety $(r=.425, p<.01)$ and no correlation between healthy orthorexia and social appearance anxiety $(r=.056, p>.01)$. These findings supported the concurrent and divergent validity of TOS.

The two TOS factors were shown to be reliable (orthorexia nervosa: $\rho_{\mathrm{NL}}=.82$; healthy orthorexia: $\rho_{\mathrm{NL}}=.83$ ). The hypothetical reliability was also adequate (orthorexia nervosa: $\alpha=.91, \omega=.87$; healthy orthorexia: $\alpha=.90$, $\omega=.78)$. The TOS measurement model was invariant across the independent subsamples $\left(\Delta \chi^{2}{ }_{\lambda}=399.72, d f=15, p=.748 ; \Delta \chi^{2}{ }_{\mathrm{t}}=388.19, d f=17, p=.514\right.$; 
Table 3. Descriptive Statistics for Responses of the Teruel Orthorexia Scale and Factor Loadings of the Items.

\begin{tabular}{lllrllllllll}
\hline Item & Mi & Ma & M & Md & Mo & \multicolumn{1}{c}{ SD } & \multicolumn{1}{c}{ Sk } & SE-Sk & Ku & SE-Ku & $\lambda$ \\
\hline 1 & 0 & 3 & 2.46 & 3.00 & 3.00 & .69 & -1.24 & .16 & 1.50 & .32 & .70 \\
2 & 0 & 3 & 1.17 & 1.00 & 1.00 & .86 & .37 & .16 & -.49 & .32 & .57 \\
3 & 0 & 3 & 1.51 & 2.00 & 2.00 & .90 & -.05 & .16 & -.76 & .32 & .69 \\
4 & 0 & 3 & 1.01 & 1.00 & 0 & 1.01 & .71 & .16 & -.59 & .32 & .84 \\
5 & 0 & 3 & .36 & 0 & 0 & .74 & 2.20 & .16 & 4.30 & .32 & .76 \\
6 & 0 & 3 & 1.35 & 1.00 & 2.00 & .95 & .02 & .16 & -.98 & .32 & .86 \\
7 & 0 & 3 & .99 & 1.00 & 1.00 & .85 & .59 & .16 & -.22 & .32 & .77 \\
8 & 0 & 3 & 1.61 & 2.00 & 2.00 & .91 & -.07 & .16 & -.81 & .32 & .82 \\
9 & 0 & 3 & .66 & 0 & 0 & .79 & 1.02 & .16 & .40 & .32 & .85 \\
10 & 0 & 3 & 1.24 & 1.00 & 1.00 & .90 & .24 & .16 & -.73 & .32 & .78 \\
11 & 0 & 3 & 1.60 & 2.00 & 2.00 & .95 & -.07 & .16 & -.91 & .32 & .71 \\
12 & 0 & 3 & .69 & 0 & 0 & .88 & 1.18 & .16 & .60 & .32 & .80 \\
13 & 0 & 3 & 1.06 & 1.00 & 1.00 & .90 & .61 & .16 & -.33 & .32 & .77 \\
14 & 0 & 3 & .16 & 0 & 0 & .49 & $3.68^{\mathrm{a}}$ & .16 & $15.27^{\mathrm{a}}$ & .32 & .66 \\
15 & 0 & 3 & .58 & 0 & 0 & .81 & 1.32 & .16 & 1.03 & .32 & .58 \\
16 & 0 & 3 & .21 & 0 & 0 & .54 & $3.05^{\mathrm{a}}$ & .16 & $10.28^{\mathrm{a}}$ & .32 & .72 \\
17 & 0 & 3 & .11 & 0 & 0 & .44 & $4.96^{\mathrm{a}}$ & .16 & $26.72^{\mathrm{a}}$ & .32 & .64 \\
\hline
\end{tabular}

Note. $\mathrm{Mi}=$ Minimum, $\mathrm{Ma}=$ Maximum, $\mathrm{M}=$ Mean, $\mathrm{Md}=$ Median; $\mathrm{Mo}=$ Mode, $\mathrm{SD}=$ Standard Deviation, Sk $=$ Skewness, SE-Sk $=$ Skewness' Standard Error, Ku $=$ Kurtosis, SE-Ku $=$ Kurtosis' Standard Error, $\lambda=$ Factor loading.

${ }^{a}$ High values to skewness $(>3)$ and/or kurtosis $(>10)$.

$\left.\Delta \chi_{\text {res }}^{2}=440.34, d f=17, p=.252\right)$ and across male and female subsamples $\left(\Delta \chi_{\lambda}^{2}=426.52, d f=15, p=.639 ; \Delta \chi^{2}{ }_{\mathrm{t}}=414.35, d f=17, p=.146 ; \Delta \chi_{\text {res }}^{2}=487.60\right.$, $d f=17, p=.074)$. This result revealed the instrument's external validity.

The average TOS scores obtained were $.55(S D=.51)$ for orthorexia nervosa (male sample $=.47 \quad[S D=.44]$, female sample $=.71 \quad[S D=.58]$ ) and 1.37 $(S D=.61)$ for healthy orthorexia (male sample $=1.41 \quad[S D=.59]$, female sample $=1.31[S D=.64])$. For the healthy orthorexia factor, no significant difference was observed between men and women $(F=1.404, d f=1, p=.237$, partial eta squared $\left[\eta_{p}^{2}\right]=.006$ ). On the other hand, women had higher scores for orthorexia nervosa compared to men $\left(F=11.719, d f=1, p=.001, \eta_{p}^{2}=.050\right)$. There was no significant correlation between age and both factors of the TOS (orthorexia nervosa: $r=.114, p=.086$; healthy orthorexia: $r=.018, p=.783$ ) or between BMI and the healthy orthorexia factor $(r=.006, p=.931)$. The correlation between BMI and orthorexia nervosa factor was negative and significant $(r=-.145, p=.030)$.

The frequency of individuals classified according to the mean scores of each TOS factor is shown in Table 4. Most participants did not have characteristic aspects of orthorexia nervosa $(94.7 \%)$ or even healthy orthorexia $(58.8 \%)$, as 


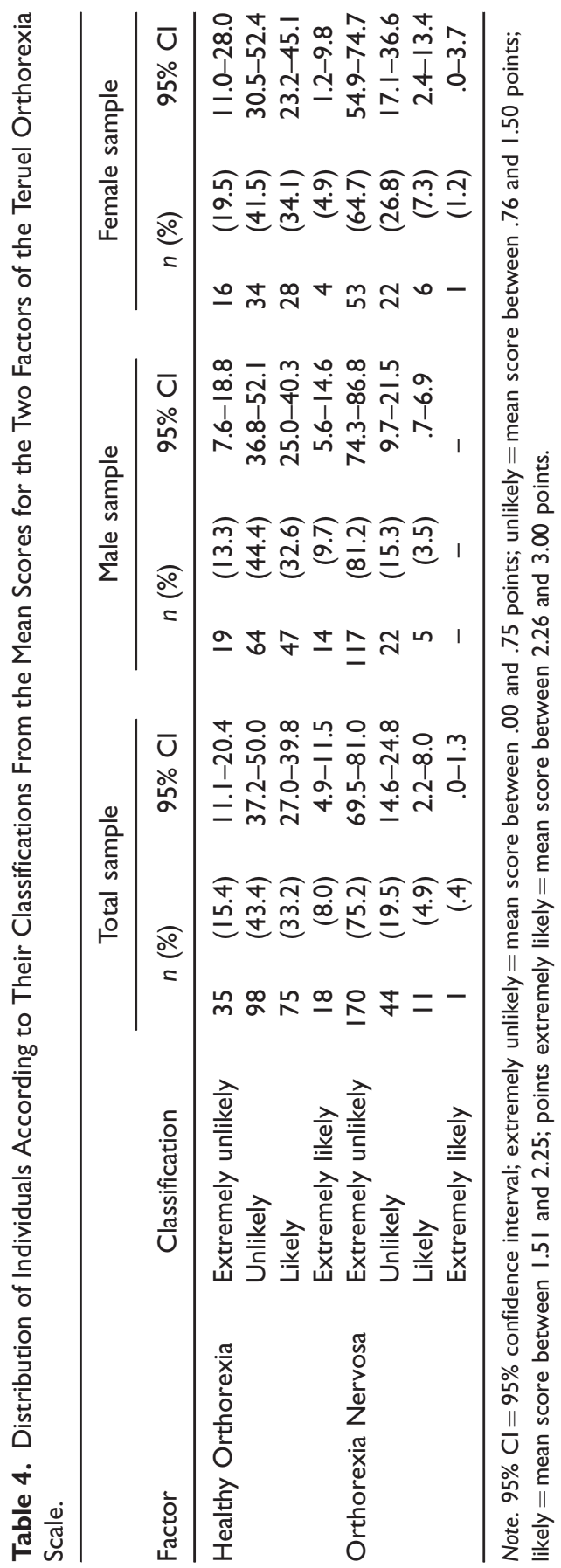


defined by scores below the 50th percentile. On the other hand, 5.3\% $(n=12)$ of the individuals presented pathological behaviors and $41.2 \%(n=93)$ presented non-pathological behaviors in relation to healthy eating, and of these, ten (six women, four men) were more likely to have both behaviors of orthorexia nervosa and healthy orthorexia.

\section{Discussion}

As no Portuguese version of the TOS was available prior to this study, our first objective was to cross-culturally adapt the Spanish TOS to the Brazilian context in order to expand the use of the instrument. Secondly, we evaluated the bifactorial model of the TOS with a sample of Brazilian gym users and found adequate validity and reliability data with the new Portuguese instrument. Thirdly, we calculated the average scores among these participants for each factor of the TOS and presented the frequency of behaviors characteristic of orthorexia nervosa and of healthy orthorexia among the participants. These results can be useful for future research and clinical protocols aimed at understanding orthorexia behaviors in a population of regular exercisers.

The process of cross-cultural adaptation of the TOS to the Portuguese language was carried out following international protocols (Beaton et al., 2000; Reichenheim \& Moraes, 2007). An adjustment in the TOS to the Brazilian context was made, without compromising the original content of the scale (Barrada \& Roncero, 2018). Thus, the Brazilian Portuguese version of the TOS was established, with good understandability by young adults.

The psychometric evaluation of the TOS indicated adequate validity of the instrument's bi-factorial model to the data without the need for any modification. In the original study, Barrada and Roncero (2018) also found good indicators of the fit of the TOS to a sample of Spanish individuals. In our study, three items had high values for skewness and kurtosis, as also reported in the original study. However, these items presented high factor loadings for our sample and their exclusion did not result in a better fit of the model; therefore, the items were kept, respecting the original proposed of the instrument. As the factorial model of the TOS was the same for Brazilian and Spanish respondents, future studies could be developed to investigate whether these cultures share similarities with other cultures with regard to healthy eating habits.

To our knowledge, we assessed for the first time the convergent and discriminant validity of the TOS factors using the accepted Fornell and Larcker's (1981) criteria. It is worth noting that the average variance extracted of the healthy orthorexia factor is equivalent to the $r^{2}$ indicating that the discriminant validity was borderline; therefore, further studies are needed to confirm this result. The significant correlation between orthorexia nervosa and social appearance anxiety shows that these concepts were related. Similar results were reported in the original study of the TOS (Barrada \& Roncero, 2018) in which orthorexia 
nervosa was significantly correlated with negative affect $(r=.28, p<.05)$ and body appearance $(r=-.25, p<.05)$. On the other hand, there was no significant correlation between healthy orthorexia and social appearance anxiety, indicating that these concepts were divergent.

In addition, corroborating prior literature (Barrada \& Roncero, 2018; Barthels et al., 2019; Depa et al., 2019), we found hypothetical reliability to be adequate, and we found good $\rho_{\mathrm{NL}}$ values, indicating the instrument's reliability. Moreover, we found the TOS bi-factorial model to be invariant through independent subsamples and between male and female subsamples, supporting the adequacy of the TOS model in different groups.

Mean scores of the TOS for comparing participant subgroups on dimensions of orthorexia nervosa and healthy orthorexia were new analyses that were not present in the original TOS study that relied on the sum score. We found that mean scores for healthy orthorexia were not different between men and women, but women showed higher values for mean scores of orthorexia nervosa. These results should be interpreted with caution, since this is a cross-sectional study and the effect size of this analysis was not high. Furthermore, the relationship between orthorexia and sex is controversial in prior literature (McComb \& Mills, 2019), as findings from some studies were consistent with our finding that orthorexia nervosa was more common among women than men (Dell'Osso et al., 2018; Missbach et al., 2015; Parra-Fernandez et al., 2018; Rudolph, 2018) while other studies have not validated this result. McComb and Mills (2019), suggested that this relationship between sex and orthorexia nervosa prevalence may be dependent upon sample characteristics, including samples in which a greater proportion of women were included in the surveys. In addition, severe food control and intense physical exercise are common behaviors among women who wish to change their body shape (Grogan, 2017). According to Barthels et al. (2020), orthorexic eating behaviors were associated with a drive for thinness and body dissatisfaction among young women in Germany. Further research is needed to explore more specifically the effect of body image on orthorexic eating behaviors, especially in men.

We found no correlation between age and orthorexia, unlike some previous studies showing that young people who exercise were more likely to have signs of orthorexia nervosa (Almeida et al., 2018; Bóna et al., 2019). Our data's divergence from this prior research may have been related to our participants' ages having been less variable (18 to 40 years). While, we did find BMI to be significantly negatively related to orthorexia nervosa $(r=-.145, p=.030)$, this result should be interpreted with caution. Missbach and colleagues (2015) reported a weak negative correlation between the same variables $(r=-.09$, $p<.01$ ), but, in their review, McComb and Mills (2019) pointed to divergent results in the literature on this relationship, with some studies reporting no correlation and others, significant correlations. Future studies should develop and test theoretical causal models to verify any relationship between age, BMI, 
and orthorexia. In addition, body composition (i.e., distribution of lean and fat mass) might prove to be a more accurate parameter than BMI to study the relationship between orthorexia nervosa and body mass.

As there is no "gold standard" definition of orthorexia for establishing cutoff points for the TOS, we used percentiles of the participants' responses on the Likert-type scale to classify individuals regarding the probability that they presented characteristics of pathological or non-pathological eating behaviors. This could be considered a study limitation, though this method has been adopted previously for other scales without established categories (da Silva et al., 2021). The use of percentiles allows the TOS to be applied in clinical and scientific studies to identify the frequency of orthorexia nervosa and healthy orthorexia behaviors/symptoms, but further clinical investigations are needed to support this proposal.

Most participants $(94.7 \%)$ did not present orthorexia nervosa behaviors; perhaps this indicates that individuals who regularly exercise generally follow healthy diets in a positive way and not as an aspect of obsessive dysfunctional behavior (Segura-Garcia et al., 2012). This low frequency of orthorexia nervosa in our sample is consistent with findings in some previous studies (Depa et al., 2017; Strahler et al., 2018), though some other studies reported high rates (Agopyan et al., 2019; Turner \& Lefevre, 2017). Thus, our results should be interpreted with caution, and the different methods of evaluation between studies should be considered (McComb \& Mills, 2019), as some prior studies used instruments with inadequate psychometric properties that may have overestimated the prevalence of orthorexia nervosa (Valente et al., 2019).

Similarly, most of our participants did not present behaviors of healthy orthorexia, indicating that most were not highly interested in healthy eating. Indeed, $41.2 \%$ of the sample showed non-pathological eating habits. This result shows the importance of independently assessing both healthy orthorexia and orthorexia nervosa in order to avoid over-identifying the incidence of pathological behaviors when many participants may be simply reporting an awareness of the benefits of a healthy diet (Depa et al., 2019). This risk may be particularly high when sampling regular exercisers who may be particularly informed about healthy eating as part of a healthy lifestyle (Bóna et al., 2019).

\section{Limitations and Directions for Future Research}

Apart from potential study limitations already discussed, we used a specific nonprobabilistic sample (i.e., gym users) that is not representative of the general population, limiting any generalization of these results to individuals who exercise within gyms from other regions of Brazil. Second, we did not collect data on specific dietary patterns (e.g., vegetarianism), nor did we gather data from professional athletes (e.g., triathletes), though both of these variables may be of interest in beliefs about healthy eating. Third, we did not present test-retest 
measures to verify the stability of the scale. Another limitation was our reliance on self-report measures to calculate BMI. While self-reported weight and height have been shown to be highly correlated with actual measures of weight and height, there can be distorted self-perceptions of these variables among certain respondents. Finally, our cross-sectional study design does not allow inferences of cause-and-effect relationships, and longitudinal and prospective research is needed for drawing those conclusions.

\section{Conclusion}

We conducted the first cross-cultural adaptation of the original Spanish TOS into Portuguese and tested it with adults who regularly exercise within gyms in Brazil. Our results showed that the Portuguese version produced in Brazil presented valid and reliable data, which can assist further research regarding the psychology of eating. Additionally, we found invariance of the original model (bi-factorial) across independent samples and sexes. Moreover, we identified a low frequency of orthorexia nervosa behaviors $(5.3 \%)$ and a moderate frequency of healthy orthorexia behaviors $(41.2 \%)$ among our participants. Considering that our data were obtained from a specific sample (i.e., gym users), future research should address other samples to expand the use of the TOS in other Brazilian contexts. In the meantime, psychologists, nutritionists, physical educators, doctors, and other health professionals can develop psychoeducational actions for awareness on the harmful effects for physical and psychological health of adopting dysfunctional eating habits such as restrictive and inflexible diets.

\section{Acknowledgments}

We thank the School of Pharmaceutical Sciences at UNESP for institutional support.

\section{Contributions}

W. R. S. performed the analysis and interpretation of data and wrote the first draft of the article, taking the lead in the research. C. H. C. M. collected the data and contributed to write the first draft of the article. A. N. N. assisted with data collection and revised the article. J. M. assisted in the data analysis and revised the article. J. A. D. B. C. contributed to the conception of the study and critically revised the article.

\section{Ethical Statement}

This study was approved by the Research Ethics Committee of the School of Pharmaceutical Sciences of the UNESP, campus of Araraquara (CAAE: 22051619.8.0000.5426). This study followed the guidelines of the Declaration of Helsinki. All participants gave consent by signing the Free Informed Consent form. 


\section{Declaration of Conflicting Interests}

The author(s) declared no potential conflicts of interest with respect to the research, authorship, and/or publication of this article.

\section{Funding}

The author(s) disclosed receipt of the following financial support for the research, authorship, and/or publication of this article: The study was financially supported in part by the Coordenação de Aperfeiçoamento de Pessoal de Nível Superior (CAPES; Finance Code 001) and by the National Council of Technological and Scientific Development (CNPq; 168533/2018-9).

\section{References}

ABEP. (2020). Associação Brasileira de Empresas de Pesquisa. Critério de Classificação Econômica Brasil [Brazilian Economic Classification Criteria]. http://www.abep.org/ criterio-brasil

Agopyan, A., Kenger, E. B., Kermen, S., Ulker, M. T., Uzsoy, M. A., \& Yetgin, M. K. (2019). The relationship between orthorexia nervosa and body composition in female students of the nutrition and dietetics department. Eating and Weight Disorders, 24(2), 257-266. https://doi.org/10.1007/s40519-018-0565-3

Almeida, C., Vieira Borba, V., \& Santos, L. (2018). Orthorexia nervosa in a sample of Portuguese fitness participants. Eating and Weight Disorders, 23(4), 443-451. https:// doi.org/10.1007/s40519-018-0517-y

Alvarenga, M. S., Martins, M. C., Sato, K. S., Vargas, S. V., Philippi, S. T., \& Scagliusi, F. B. (2012). Orthorexia nervosa behavior in a sample of Brazilian dietitians assessed by the Portuguese version of ORTO-15. Eating and Weight Disorders, 17(1), e29-e35. https://doi.org/10.1007/BF03325325

American Psychiatric Association. (2013). Diagnostic and statistical manual of mental disorders (5th ed.). Author.

Anastasi, A., \& Urbina, S. (1997). Psychological testing (7th ed.). Prentice Hall.

Barrada, J. R., \& Roncero, M. (2018). Bidimensional structure of the orthorexia: Development and initial validation of a new instrument. Anales de Psicología, 34(2), 283-291. https://doi.org/10.6018/analesps.34.2.299671

Barthels, F., Barrada, J. R., \& Roncero, M. (2019). Orthorexia nervosa and healthy orthorexia as new eating styles. PloS One, 14(7), e0219609. https://doi.org/10.1371/ journal.pone.0219609

Barthels, F., Kisser, J., \& Pietrowsky, R. (2020). Orthorexic eating behavior and body dissatisfaction in a sample of young females. Eating and Weight Disorders. https://doi. org/10.1007/s40519-020-00986-5

Barthels, F., Meyer, F., \& Pietrowsky, R. (2015). Duesseldorf orthorexia scaleConstruction and evaluation of a questionnaire measuring orthorexic eating behavior [die düsseldorfer orthorexie skala-Construktion und evaluation eines fragebogens zur erfassung orthorektischen ernährungsverhaltens. Zeitschrift Für Klinische Psychologie Und Psychotherapie, 44(2), 97-105. https://doi.org/10.1026/1616-3443/a000310

Bauer, S. M., Fuste, A., Andres, A., \& Saldana, C. (2019). The Barcelona Orthorexia Scale (BOS): Development process using the Delphi method. Eating and Weight Disorders, 24(2), 247-255. https://doi.org/10.1007/s40519-018-0556-4 
Beaton, D. E., Bombardier, C., Guillemin, F., \& Ferraz, M. B. (2000). Guidelines for the process of cross-cultural adaptation of self-report measures. Spine, 25(24), 3186-3191. https://doi.org/10.1097/00007632-200012150-00014

Bert, F., Gualano, M. R., Voglino, G., Rossello, P., Perret, J. P., \& Siliquini, R. (2019). Orthorexia nervosa: A cross-sectional study among athletes competing in endurance sports in Northern Italy. PloS One, 14(8), e0221399. https://doi.org/10.1371/journal. pone.0221399

Bóna, E., Szel, Z., Kiss, D., \& Gyarmathy, V. A. (2019). An unhealthy health behavior: Analysis of orthorexic tendencies among Hungarian gym attendees. Eating and Weight Disorders, 24(1), 13-20. https://doi.org/10.1007/s40519-018-0592-0

Bratman, S. (1997). Health food junkie: Obsession with dietary perfection can sometimes do more harm than good, says one who has been there. Yoga Journal, 136, 42-46. https://www.beyondveg.com/bratman-s/hfj/hf-junkie-1a.shtml

Bratman, S. (2017). Orthorexia vs. theories of healthy eating. Eating and Weight Disorders, 22(3), 381-385. https://doi.org/10.1007/s40519-017-0417-6

Bratman, S., \& Knight, D. (2000). Health food junkies: Orthorexia nervosa: Overcoming the obsession with healthful eating (1st ed.). Broadway.

Brown, T. A. (2015). Confirmatory factor analysis for applied research (2nd ed.). Guilford Press.

Cena, H., Barthels, F., Cuzzolaro, M., Bratman, S., Brytek-Matera, A., Dunn, T., Varga, M., Missbach, B., \& Donini, L. M. (2019). Definition and diagnostic criteria for orthorexia nervosa: A narrative review of the literature. Eating and Weight Disorders, 24(2), 209-246. https://doi.org/10.1007/s40519-018-0606-y

Cicchetti, D. V. (1994). Guidelines, criteria, and rules of thumb for evaluating normed and standardized assessment instruments in psychology. Psychological Assessment, 6(4), 284-290. https://doi.org/10.1037/1040-3590.6.4.284

Coluci, M. Z. O., \& Alexandre, N. M. C. (2009). Development of a questionnaire to evaluate the usability of assessment instruments. Revista de Enfermagem, 17(3), 378-382.

da Silva, W. R., Maroco, J., \& Campos, J. (2021). Examination of the factorial model of a scale developed to assess body satisfaction in the Brazilian context: A study with people 18 to 40 years old. Eating and Weight Disorders. https://doi.org/10.1007/ s40519-020-01102-3

De Onis, M., Onyango, A. W., Borghi, E., Siyam, A., Nishida, C., \& Siekmann, J. (2007). Development of a WHO growth reference for school-aged children and adolescents. Bulletin of the World Health Organization, 85(9), 660-667. https://doi.org/10.1590/ S0042-96862007000900010

Dell'Osso, L., Carpita, B., Muti, D., Cremone, I. M., Massimetti, G., Diadema, E., Gesi, C., \& Carmassi, C. (2018). Prevalence and characteristics of orthorexia nervosa in a sample of university students in Italy. Eating and Weight Disorders, 23(1), 55-65. https://doi.org/10.1007/s40519-017-0460-3

Depa, J., Barrada, J. R., \& Roncero, M. (2019). Are the motives for food choices different in orthorexia nervosa and healthy orthorexia? Nutrients, 11(3), 697-614. https:// doi.org/10.3390/nu11030697

Depa, J., Schweizer, J., Bekers, S. K., Hilzendegen, C., \& Stroebele-Benschop, N. (2017). Prevalence and predictors of orthorexia nervosa among German students using the 
21-item-DOS. Eating and Weight Disorders, 22(1), 193-199. https://doi.org/10.1007/ s40519-016-0334-0

Domingues, R. B., \& Carmo, C. (2021). Orthorexia nervosa in yoga practitioners: Relationship with personality, attitudes about appearance, and yoga engagement. Eating and Weight Disorders, 26(3), 789-795. https://doi.org/10.1007/s40519-02000911-w

Donini, L. M., Marsili, D., Graziani, M. P., Imbriale, M., \& Cannella, C. (2005). Orthorexia nervosa: Validation of a diagnosis questionnaire. Eating and Weight Disorders, 10(2), e28-e32. https://doi.org/10.1007/BF03327537

Dunn, T. M., \& Bratman, S. (2016). On orthorexia nervosa: A review of the literature and proposed diagnostic criteria. Eating Behaviors, 21(2), 11-17. https://doi.org/10. 1016/j.eatbeh.2015.12.006

Fornell, C., \& Larcker, D. F. (1981). Evaluating structural equation models with unobservable variables and measurement error. Journal of Marketing Research, 18(1), 39-50. https://doi.org/10.2307/3151312?uid = 3737664\&uid = 2\&uid = 4\&sid = 21103223270061

Gadermann, A. M., Guhn, M., \& Zumbo, B. D. (2012). Estimating ordinal reliability for Likert-type and ordinal item response data: A conceptual, empirical, and practical guide. Practical Assessment, Research \& Evaluation, 17(3), 1-13. https://doi.org/10. 7275/n560-j767

Genz, A., Kenkel, B., \& Azzalini, A. (2015). Vectorized bivariate normal CDF. https:// www.github.com/brentonk/pbivnorm

Gleaves, D. H., Graham, E. C., \& Ambwani, S. (2013). Measuring "orthorexia”: development of the eating habits questionnaire. The International Journal of Educational and Psychological Assessment, 12(2), 1-18.

Grogan, S. (2017). Body image: Understanding body dissatisfaction in men, women and children (3rd. ed.). Routledge.

Hair Jr., J. F., Black, W. C., Babin, B., \& Anderson, R. E. (2019). Multivariate data analysis (8th ed.). Cengage Learning EMEA.

Hart, T. A., Flora, D. B., Palyo, S. A., Fresco, D. M., Holle, C., \& Heimberg, R. G. (2008). Development and examination of the social appearance anxiety scale. Assessment, 15(1), 48-59. https://doi.org/10.1177/1073191107306673

$\mathrm{Hu}, \mathrm{L} .$, \& Bentler, P. M. (1999). Cutoff criteria for fit indexes in covariance structure analysis: Conventional criteria versus new alternatives. Structural Equation Modeling, 6(1), 1-55. https://doi.org/10.1080/10705519909540118

Jorgensen, T. D., Pornprasertmanit, S., Schoemann, A. M., \& Rosseel, Y. (2020). semTools: Useful tools for structural equation modeling. https://www.CRAN.R-proj ect.org $/$ package $=$ semTools

Kim, S., Lu, Z., \& Cohen, A. S. (2020). Reliability for tests with items having different numbers of ordered categories. Applied Psychological Measurement, 44(2), 137-149. https://doi.org/10.1177/0146621619835498

Lorenzon, L. F. L., Minossi, P. B. P., \& Pegolo, G. E. (2020). Ortorexia nervosa e imagem corporal em adolescentes e adultos [Orthorexia nervosa and body image in adolescents and adults]. Jornal Brasileiro de Psiquiatria, 69(2), 117-119. https://doi. org/10.1590/0047-2085000000266

Marôco, J. (2021). Análise de equações estruturais [Structural equation analysis] (3rd ed.). ReportNumber, Lda. 
McComb, S. E., \& Mills, J. S. (2019). Orthorexia nervosa: A review of psychosocial risk factors. Appetite, 140(3), 50-75. https://doi.org/10.1016/j.appet.2019.05.005

Missbach, B., Dunn, T. M., \& Konig, J. S. (2017). We need new tools to assess orthorexia nervosa. A commentary on "prevalence of orthorexia nervosa among college students based on Bratman's test and associated tendencies. Appetite, 108, 521-524. https://doi. org/10.1016/j.appet.2016.07.010

Missbach, B., Hinterbuchinger, B., Dreiseitl, V., Zellhofer, S., Kurz, C., \& Konig, J. (2015). When eating right, is measured wrong! a validation and critical examination of the ORTO-15 questionnaire in German. PloS One, 10(8), e0135772. https://doi.org/ 10.1371/journal.pone.0135772

Mitrofanova, E., Pummell, E., Martinelli, L., \& Petroczi, A. (2021). Does ORTO-15 produce valid data for 'orthorexia nervosa'? A mixed-method examination of participants' interpretations of the fifteen test items. Eating and Weight Disorders, 26(3), 897-909. https://doi.org/10.1007/s40519-020-00919-2

Muthén, L. K., \& Muthén, B. O. (2017). MPlus: Statistical analysis with latent variables user's guide. https://www.StatModel.com

Novara, C., Pardini, S., Maggio, E., Mattioli, S., \& Piasentin, S. (2021). Orthorexia nervosa: Over concern or obsession about healthy food? Eating and Weight Disorders. https://doi.org/10.1007/s40519-021-01110-x

Oberle, C. D., De Nadai, A. S., \& Madrid, A. L. (2021). Orthorexia nervosa inventory (ONI): Development and validation of a new measure of orthorexic symptomatology. Eating and Weight Disorders, 26(2), 609-622. https://doi.org/10.1007/s40519-02000896-6

Parra-Fernandez, M. L., Rodriguez-Cano, T., Onieva-Zafra, M. D., Perez-Haro, M. J., Casero-Alonso, V., Fernandez-Martinez, E., \& Notario-Pacheco, B. (2018). Prevalence of orthorexia nervosa in university students and its relationship with psychopathological aspects of eating behaviour disorders. BMC Psychiatry, 18(1), 364-368. https://doi.org/10.1186/s12888-018-1943-0

Reichenheim, M. E., \& Moraes, C. L. (2007). Operationalizing the cross-cultural adaptation of epidemological measurement instruments. Revista de Saúde Pública, 41(4), 665-673. https://doi.org/10.1590/S0034-89102006005000035

Revelle, W. (2019). Psych: Procedures for psychological, psychometric, and personality research. https://www.CRAN.R-project.org/package $=$ psych

Rossel, Y. (2012). Lavaan: An R package for structural equation modeling. Journal of Statistical Software, 48(2), 1-36. https://doi.org/10.18637/jss.v048.i02

Rudolph, S. (2018). The connection between exercise addiction and orthorexia nervosa in German fitness sports. Eating and Weight Disorders, 23(5), 581-586. https://doi.org/ 10.1007/s40519-017-0437-2

Segura-Garcia, C., Papaianni, M. C., Caglioti, F., Procopio, L., Nistico, C. G., Bombardiere, L., Ammendolia, A., Rizza, P., De Fazio, P., \& Capranica, L. (2012). Orthorexia nervosa: A frequent eating disordered behavior in athletes. Eating and Weight Disorders, 17(4), e226-e233. https://doi.org/10.3275/8272

Strahler, J. (2020). The dark side of healthy eating: Links between orthorexic eating and mental health. Nutrients, 12(12), 3662-3612. https://doi.org/10.3390/nu12123662

Strahler, J. (2021). Trait mindfulness differentiates the interest in healthy diet from orthorexia nervosa. Eating and Weight Disorders, 26(3), 993-998. https://doi.org/10. 1007/s40519-020-00927-2 
Strahler, J., Haddad, C., Salameh, P., Sacre, H., Obeid, S., \& Hallit, S. (2020). Crosscultural differences in orthorexic eating behaviors: Associations with personality traits. Nutrition, 77(1), 110811-110811. https://doi.org/10.1016/j.nut.2020.110811

Strahler, J., Hermann, A., Walter, B., \& Stark, R. (2018). Orthorexia nervosa: A behavioral complex or a psychological condition? Journal of Behavioral Addictions, 7(4), 1143-1156. https://doi.org/10.1556/2006.7.2018.129

Turner, P. G., \& Lefevre, C. E. (2017). Instagram use is linked to increased symptoms of orthorexia nervosa. Eating and Weight Disorders, 22(2), 277-284. https://doi.org/10. 1007/s40519-017-0364-2

Valente, M., Syurina, E. V., \& Donini, L. M. (2019). Shedding light upon various tools to assess orthorexia nervosa: A critical literature review with a systematic search. Eating and Weight Disorders, 24(4), 671-682. https://doi.org/10.1007/s40519-019-00735-3

World Health Organization. (2000). Obesity: Preventing and managing the global epidemic. Technical Report Series. Geneva: World Health Organization. https://www.who. int/nutrition/publications/obesity/WHO_TRS_894/en/

World Health Organization. (2018). International classification of diseases for mortality and morbidity statistics (11th Revision). https://icd.who.int/browse11/1-m/en

Yang, Y., \& Green, S. B. (2015). Evaluation of structural equation modeling estimates of reliability for scales with ordered categorical items. Methodology, 11(1), 23-34. https:// doi.org/10.1027/1614-2241/a000087

Zumbo, B. D., Gadermann, A. M., \& Zeisser, C. (2007). Ordinal versions of coefficients alpha and theta for Likert rating scales. Journal of Modern Applied Statistical Methods, 6(1), 21-29. https://doi.org/10.22237/jmasm/1177992180

\section{Author Biographies}

Wanderson Roberto da Silva, Ph.D., is a Nutritionist. He is a researcher at the São Paulo State University (UNESP) and the Federal University of Alfenas (UNIFAL). He has experience in the areas of Body Image and Eating Behavior with an emphasis on validity of psychometric instruments.

Carlos Hernani Cruz Marmol, M.Sc., Biomedical, is a Master in Foods and Nutrition, subarea of Nutritional Sciences at São Paulo State University (UNESP).

Angela Nogueira Neves, Ph.D., is a Senior Lecturer at Physical Education School of Brazilian Army. She has experience in the areas of Body Image and Physical Exercise.

João Marôco, Ph.D., is an Associate Professor with habilitation of ISPA - Instituto Universitário where he teaches statistics and research methods. His research interest are in the psychometric evaluation and scale development using advanced statistical methods.

Juliana Alvares Duarte Bonini Campos, Ph.D., is an Associate professor at the School of Pharmaceutical Sciences of São Paulo State University (UNESP). She has experience in biostatistics and scientific methodology with an emphasis on validity of scales. Under her guidance, graduate and undergraduate students conduct studies related to mental health, body image, eating behavior, appetite, pain, occupational health, and quality of life. 